phosphorescence, and many allied subjects will probably be accounted for by the discussion of resonance and forced oscillations, to which the system is susceptible.

The above results were communicated to the Physicomathematical Society of Tokyo in December last; the details of calculation will probably appear in the Philosophical Magazine in the near future. H. NAGAOKA.

Physical Laboratory, Tokyo University, January 18.

\section{Science in the Navy.}

IN view of the important articles which appeared in NATURE last year on the question of science in the navy, it seems desirable to inquire into the amount of encouragement which is now given to young lieutenants to adopt either of the more scientific branches of their profession.

Apart from zeal for the service and the love of knowledge, the most potent incentive to their doing so lies in the promise of early promotion to commander. Now, of the thirty-five lieutenants promoted on January $\mathrm{I}$ last, the following analysis will show that the more scientific officer has no advantage over his fellow as regards promotion. The periods between promotion to lieutenant and to commander were :-

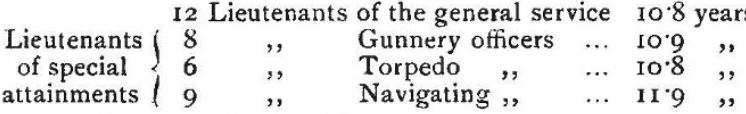

From the above it is evident that no advantage accrued to those who had the ability to attain the scientific knowledge required for their respective branches, whilst the future of those who selected navigation was marred by having to wait a year longer than any other officer.

Lastly, it may be remarked that it argues well for a service in which science is courted by so many in spite of the small encouragement given in this matter of promotion.

\section{Organisms and Meteorites.}

I sirovid be glad to know whether anyone has ever attempted to test the hypothesis of Helmholtz and Lord Kelvin that meteorites are possibly the carriers of organised matter. By pulverising a portion taken from the interior of a meteorite it would, I should suppose, be easy to dissolve out and detect any organic matter that was there. The result in any particular case would probably be negative; still, wilder experiments have been tried before now.

Trinity College, Cambridge, February i5 JAMES WARD.

\section{The Gordiidæ in Folk-lore.}

THE sudden appearance of the Gordiidæ or hair worms in puddles of water or similar situations has caused the primitive peoples of many countries to evolve a theory of their seemingly mysterious origin. In parts of Scotland they are believed to be the intermediate stage in the development of a horse-hair into an eel ; in Iceland and the Færöes, and also in some of the Malayan islands, they are thought to come down with the rain; in the Malay Peninsula they are said to be the offspring of an unnatural union between an earthworm and a female mantis, and to turn into a fern (Lygodium sp.), the creeping rhizome of which some of them (for example, Chorodes montoni, Camer.) closely resemble. (I found that a very large proportion of the true Mantidæ were infested by them in the Malay States.) In the same country, by an application of the principle of the doctrine of signatures, they are used in the manufacture of a hair-wash. I have thought that it might be interesting to trace out the beliefs held about them among different races, but I find references to them extremely scanty in ethnographical or general literature. If any of your correspondents could furnish information of the kind I would be extremely grateful, for I believe that an interesting contribution to the biological philosophy of savages might be made by collecting and analysing the different theories held by primitive peoples regarding a small and easily recognised group of animals like the Gordiidæ.

34 Charlotte Square, Edinburgh.

$$
\text { NELson AnNandale. }
$$

\section{THE ANTARCTIC EXPEDITIONS.}

$\mathrm{M}^{\mathrm{O}}$

RE or less detailed accounts have now been published of all the three expeditions-German, Swedish, and Scottish--which, following the lead of the British party in the Discovery, have during the past two years striven to extend the bounds of knowledge in the far southern regions. Some idea can therefore be gained of the scientific results obtained in various directions. It is a remarkable illustration of the independence of climatic conditions on mere latitude that, while each of the expeditions wintered outside the Antarctic circle, the rigours experienced have hardly been exceeded in the case of expeditions which have wintered more than $10^{\circ}$ nearer the pole in both hemispheres.

To begin with the work of the Swedish party under Dr. Nordenskjöld, of which summaries have been given both in the Times and in the Geographical Journal, it is mainly of the contributions to meteorology and geology that it is yet possible to speak, though when the magnetic observations have been worked out, results of no less importance may be expected. The value both of the meteorological and magnetic work has been greatly enhanced by the enforced detention during two winters, a much more effective basis of comparison with the observations of other expeditions and stations being thus supplied. Some useful work from a purely geographical point of view has also been accomplished, our knowledge of the contours of the land masses to the south of South America having received welcome additions, mainly as the result of two separate sledge expeditions undertaken during the two winters. The winter station, it will be remembered, was established on the eastern side of Louis Philippe Land, the northern extremity of the mass known further south as Graham Land. It was itself on an island lying to the east of the main mass, but although this appears to be fringed on this side by a regular archipelago of islands separated by wide channels, it was demonstrated-and this is one of the chief geographical results of the expedition-that the larger mass runs continuously southward from Louis Philippe Land to King Oscar Land. It is formed by a high range of mountain peaks separated by large glaciers, and further inland passing into a level icecovered plateau. Within the outer limit of the archipelago an ice-sheet extended, bounded by a formidable ice barrier running from east to west in the neighbourhood of Christensen Island (an extinct volcano). The conditions of this ice-sheet recalled those of Ross's great ice-barrier on the opposite side of the Antarctic, and, as was found by Captain Scott and his companions on their great southern sledge journey, it was separated from the land by wide, deep, and impassable crevasses. This was ascertained during the first winter expedition, which lasted from September 30 to November 7,1902 , and had its furthest point in $66^{\circ} \mathrm{S}$., $62^{\circ} \mathrm{W}$. During the second winter the leader, with one companion only, explored the channels leading north behind the islands towards Erebus Gulf. The scenery here was found to be of the grandest kind; on one side was the magnificent range of King Oscar Land, on the other a large archipelago forming a remarkable contrast to the former, and made up of tufaceous volcanic rocks, with sounds, glaciers, and promontories, all dominated by the shining blue-white prominent peak of Mount Haddington, probably formed by a mighty crater. It was during this expedition that Dr. Nordenskjöld luckily fell in with Dr. Andersson and Lieut. Duse, who had left the Antarctic before the disaster which befel it, and had spent the winter in that inhospitable region with only a summer outfit.

Throughout the time spent in the far south, the 